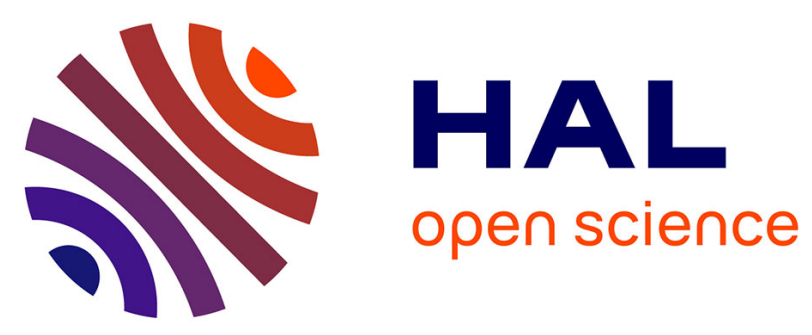

\title{
Quantitative Dietary Exposure Assessment of the Catalonian Population (Spain) to the Mycotoxin Deoxynivalenol
}

German Cano-Sancho, Jean-Pierre Gauchi, Vicent Sanchis, Sonia Marín, Antonio J. Ramos

\section{To cite this version:}

German Cano-Sancho, Jean-Pierre Gauchi, Vicent Sanchis, Sonia Marín, Antonio J. Ramos. Quantitative Dietary Exposure Assessment of the Catalonian Population (Spain) to the Mycotoxin Deoxynivalenol. Food Additives and Contaminants, 2011, 28 (8), pp.1. 10.1080/19440049.2011.576445 . hal-00701869

\section{HAL Id: hal-00701869 \\ https://hal.science/hal-00701869}

Submitted on 27 May 2012

HAL is a multi-disciplinary open access archive for the deposit and dissemination of scientific research documents, whether they are published or not. The documents may come from teaching and research institutions in France or abroad, or from public or private research centers.
L'archive ouverte pluridisciplinaire HAL, est destinée au dépôt et à la diffusion de documents scientifiques de niveau recherche, publiés ou non, émanant des établissements d'enseignement et de recherche français ou étrangers, des laboratoires publics ou privés. 


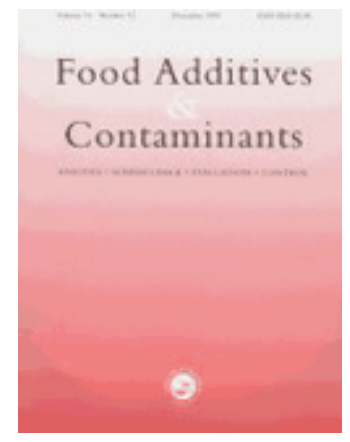

\section{Quantitative Dietary Exposure Assessment of the Catalonian Population (Spain) to the Mycotoxin Deoxynivalenol}

\begin{tabular}{|c|c|}
\hline Journal: & Food Additives and Contaminants \\
\hline Manuscript ID: & TFAC-2011-027.R1 \\
\hline Manuscript Type: & Original Research Paper \\
\hline $\begin{array}{r}\text { Date Submitted by the } \\
\text { Author: }\end{array}$ & 22-Mar-2011 \\
\hline Complete List of Authors: & $\begin{array}{l}\text { Cano-Sancho, German; University of Lleida, Food Technology } \\
\text { Gauchi, Jean-Pierre; INRA, Unité MIA } \\
\text { Sanchis, Vicent; University of Lleida, Food Technology } \\
\text { Marín, Sonia; University of Lleida, Food Technology } \\
\text { Ramos, Antonio; University of Lleida, Food Technology }\end{array}$ \\
\hline Methods/Techniques: & Exposure - prob modelling, Risk assessment, Total diet studies \\
\hline Additives/Contaminants: & Mycotoxins - trichothecenes \\
\hline Food Types: & Cereals, Bread, Baby food, Beer \\
\hline Abstract: & $\begin{array}{l}\text { The mycotoxin deoxynivalenol (DON) is one of the most common } \\
\text { contaminants of cereals worldwide, and its occurrence has been } \\
\text { widely reported in raw foods and foodstuffs, around the European } \\
\text { region, including Catalonia. In the present work, a stochastic } \\
\text { methodology has been applied to accurately assess the exposure of } \\
\text { the Catalonian population (Spain) to DON through food } \\
\text { consumption. Raw contamination data was provided by a large } \\
\text { survey conducted in this region, in addition to the raw consumption } \\
\text { data from a nutritional study specifically designed to assess the } \\
\text { dietary intake of the main foodstuffs related to DON contamination } \\
\text { for all population age groups. Contamination and consumption data } \\
\text { were combined by simulation using an essentially parametric (P-P) } \\
\text { method. The P-P method draws sampling values from distribution } \\
\text { functions fitted to consumption and contamination datasets. } \\
\text { Moreover, to quantify the accuracy and reliability of the statistics } \\
\text { estimates, we built the related confidence intervals using a Pseudo- } \\
\text { Parametric bootstrap method. Considering the results drawn from }\end{array}$ \\
\hline
\end{tabular}


2

\section{SCHOLARONE Manuscripts}

the P-P simulation method, the Catalonian population should be expected to be exposed at moderated levels of deoxynivalenol, the infants and individuals with ethnic dietary patterns being the most exposed population groups 


\title{
Quantitative dietary exposure assessment of the Catalonian population
}

\section{(Spain) to the mycotoxin deoxynivalenol}

\author{
G. Cano-Sancho $^{1 *}$, J.-P. Gauchi ${ }^{2}$, V. Sanchis ${ }^{1}$, S. Marín ${ }^{1}$ and A.J. Ramos ${ }^{1}$.
}

${ }^{1}$ Applied Mycology Unit, Food Technology Department, University of Lleida, XaRTA-UTPV, Lleida, Spain.

${ }^{2}$ Unité MIA (UR341), INRA, Jouy en Josas, France

* Corresponding author: German Cano-Sancho, Applied Mycology Unit, Food Technology Department, University of Lleida, XaRTA-UTPV, Av. Rovira Roure 191, 25198 Lleida (Spain). Phone: +34 973702 670. Fax: +34 973702 596. E-mail: gcano@ tecal.udl.cat

\begin{abstract}
The mycotoxin deoxynivalenol (DON) is one of the most common contaminants of cereals worldwide, and its occurrence has been widely reported in raw foods and foodstuffs, around the European region, including Catalonia. In the present work, a stochastic methodology has been applied to accurately assess the exposure of the Catalonian population (Spain) to DON through food consumption. Raw contamination data was provided by a large survey conducted in this region, in addition to the raw consumption data from a nutritional study specifically designed to assess the dietary intake of the main foodstuffs related to DON contamination for all population age groups. Contamination and consumption data were combined by simulation using an essentially parametric (P-P) method. The P-P method draws sampling values from distribution functions fitted to consumption and contamination datasets. Moreover, to quantify the accuracy and reliability of the statistics estimates, we built the related confidence intervals using a Pseudo-Parametric bootstrap method. Considering the
\end{abstract}


results drawn from the P-P simulation method, the Catalonian population should be expected to be exposed at moderated levels of deoxynivalenol, the infants and individuals with ethnic dietary patterns being the most exposed population groups

Keywords: Risk assessment; exposure; deoxynivalenol; cereal food

\section{Introduction}

Trichothecenes are a family of related cyclic sesquiterpenoids, which are divided into four groups (types A-D) according to their characteristic functional groups, the type A and B being the most common. Type A is represented by HT-2 toxin (HT2) and T-2 toxin (T2) and type B is most frequently represented by deoxynivalenol (DON). Trichothecenes are produced in several cereals by species of Fusarium, thus a wide range of cereal-based foods have been reported to be contaminated by these toxins (JECFA 2001), DON being one of the most common contaminants of cereals worldwide (Jelinek et al. 1989; Scott 1989).

Acute effects of food poisoning by DON in humans are abdominal pains, dizziness, headache, throat irritation, nausea, vomiting, diarrhoea, and blood in stool (Rotter et al. 1996). A tolerable daily intake (TDI) of $1 \mu \mathrm{g} / \mathrm{kg}$ body weight based on a reduction of body weight gain was established by the EC SCF (SCF 2002).

Occurrence of DON has been widely reported in raw foods and foodstuffs in European countries (JECFA 2001), confirming that food processing methods do not completely remove mycotoxins (Hazel and Patel 2004). The presence of trichothecenes in Catalonia (Spain) has been recently studied by means of a thorough methodology involving a large sampling and accurate chemical analysis. That study concluded that the occurrence of DON was high in 
cereal-based foodstuffs from Catalonian market, especially in wheat flakes, corn flakes, corn snacks, pasta and bread (Cano-Sancho et al. 2011). Cereal-based foods are the base of the energy intake in Catalonia, as well as in the other Mediterranean countries (Serra-Majem et al. 2003). Therefore, in the food safety framework, to assess the exposure of Catalonian population to DON is a priority.

To our knowledge, few studies have been published to assess the exposure to DON, and the ones that have been published have generally used deterministic approaches (SCOOP 2003). Experts have recommended the use of a stochastic approach to provide a more realistic exposure assessment, taking model uncertainties and variability into consideration. Nevertheless, there is no consensus on which specific methodology should be applied in each case (Kroes 2002; WHO 2005; EFSA 2006; Verger and Fabiansson 2008). A stochastic methodology was developed by Gauchi and Leblanc (2002) to assess the exposure of human populations to food contaminants, as in the case of the exposure of the French population to ochratoxin A (OTA). The authors proposed two simulation approaches to estimate the exposure, based on Monte Carlo simulations (using NonParametric-NonParametric and Mixed Parametric-Parametric methods), leading to the assessment of four types of bootstrap confidence intervals. The aim of this paper is to quantitatively assess the exposure of the Catalonian population (Spain) to DON.

\author{
Materials and Methods \\ Raw contamination data \\ Raw contamination data was mainly taken from the study of Cano-Sancho et al. (2011), and \\ completed with some data from the Project to Assess the Exposure of the Catalonian \\ Population to Mycotoxins (UdL-ACSA 2010).
}


In the first work, during the months of June and July 2008, corn flakes $(n=168)$, wheat flakes $(n=27)$, sweet corn $(n=185)$, corn snacks $(n=213)$, pasta $(n=201)$, beer $(n=213)$, sliced bread $(n=147)$, bread $(n=31)$, gluten-free foods $(n=12)$, ethnic foods $(n=35)$ and baby foods $(n=90)$ were obtained in six hypermarkets and supermarkets from twelve main cities (Tortosa, Tarragona, Reus, Vilanova i la Geltrú, l'Hospitalet de Llobregat, Barcelona, Terrassa, Sabadell, Mataró, Girona, Manresa and Lleida) of Catalonia, Spain, representative of $72 \%$ of the population. From each supermarket or hypermarket, 3 items (if present) of each product were randomly taken. The level of trichothecenes was determined in a total of 72 composite samples obtained by pooling the 3 items taken from each store if available (12 cities x 6 stores / city $=72$ samples / category). However, in some cases, no items were available in the store, thus, less than 72 composites could be obtained. Finally, a wide range of brands was obtained, which can be considered the majority of market share in Catalonia of these products, as well as in the rest of the Spanish market. Moreover, some commodities were selected because they are highly consumed by some population groups with different dietary patterns: baby foods, ethnic foods and gluten-free foods. DON was determined in breakfast cereals, snacks and pasta samples following extraction, clean-up, derivatization and final analysis by GC-ECD. Moreover, this mycotoxin was determined in sliced bread, sweet corn, beer, baby food, ethnic food and gluten-free food by LC-DAD. In this study, non-detected samples were assumed to be equal to the limit of detection (LOD) divided by 2, an assumption widely recognised to reduce the uncertainty of values between 0 and the LOD (GEMs/Food-WHO, 1995). Some statistics from contamination data and the related histograms are shown in Table I and Fig. 1, respectively.

Message to the editor: Place Table I and Fig.1 approximately here. 
[Table I. Occurrence of deoxynivalenol in food matrices from food available on the

\section{Catalonian market]}

[Fig 1. Contamination histograms (relative frequencies), in $\mu g g^{-1}$ for each food]

\section{Raw consumption data}

Consumption data were taken from the Project to Assess the Exposure of the Catalonian Population to Mycotoxins (UdL-ACSA 2010). This study involved a wide nutritional survey designed to specifically identify the dietary patterns of the Catalonian population in relation to the main foodstuffs susceptible to mycotoxins contamination.

Food dietary intake was assessed through a specific Food Frequency Questionnaire (FFQ), developed for the Catalonian population including those foods typically consumed in the region that may be potentially contaminated with these mycotoxins. According to World Health Organization (WHO) recommendations, studies to assess the dietary intake of chemical contaminants should show the significant intake within the standard population, as well as within all population groups that could have different dietary patterns. Therefore, five different age population groups were considered: infants (0-3 years), children (4-9 years), adolescents (10-19 years), adults (20-65 years) and seniors (> 65 years). Moreover, adult celiac sufferers and adults with ethnic dietary pattern were included in the nutritional study, and studied separately. The FFQ included 38 specific food items known to be the major foods contaminated by mycotoxins worldwide, excluding those foods not consumed in the region. Concerning consumption frequency, five response options, ranging from 'never' to 'annually', were considered. Quantities were assessed by portion size with the aid of a series of colour photograph models. Finally, 76 seniors, 720 adults, 235 adolescents, 69 children, 164 parents of infants, 70 adult celiac sufferers and 56 adults with ethnic dietary pattern were interviewed in 2008-2009 by trained interviewers. In the present study, the adults were treated separately 
Message to the editor: Place Table II and Fig.2 approximately here.

[Table II. Normalised consumption of the main foodstuff related to DON contamination by the 384 adult females $\left(\mathrm{g} \mathrm{kg}^{-1}\right.$ body weight day $\left.\left.{ }^{-1}\right).\right]$

[Fig 2. Consumption histograms (relative frequencies) for adult female consumers, in $\mu \mathrm{g} \mathrm{kg}^{-1}$ $\left.b w d a y^{-1}\right]$

Dependencies on consumption patterns can be quantified by Spearman correlation coefficients and can be taken into account by the Iman and Conover method (Iman and Conover 1982). However, Gauchi and Leblanc (2002) did not report significant differences in the results, regardless of whether or not dependencies were taken into account. We therefore did not consider dependencies in the present work.

\section{Methodology used to calculate the exposure}

In this section we recall some general aspects concerning the exposure calculations, already given in Gauchi and Leblanc (2002).

The main limitation to estimate the normalised exposure distribution of consumer populations is derived from the equation:

$$
E_{\pi}=\sum_{j=1}^{p} C_{\pi, j} T_{j}
$$

where the random variable "normalised global exposure in a consumer population $\pi$ " $\left(E_{\pi}\right)$ is a function of the random variables: "normalised consumption of the foodstuff $j$ in a consumer 
population $\pi "\left(C_{\pi, j}\right)$ and "DON concentration level of the foodstuff $j$ " $\left(T_{j}\right)$. The difficulty is due to the probability density functions $(p d f)$ since these variables are generally unknown and even if they are known, they are generally different and not independent. Moreover, the $C_{\pi, j}$ x $T_{j} p d f$ products are unknown, too.

If we assume independency between consumption $\left(C_{\pi, j}\right)$ and contamination $\left(T_{j}\right)$, as well as between their products, we can estimate the mean exposure of the population $\pi$ with the population sample $\pi_{0}$ as follows:

$$
\hat{E}_{\pi_{0}}=\sum_{j=1}^{p} \bar{C}_{\pi_{0}, j} \bar{T}_{j}
$$

Where $\bar{C}_{\pi_{0}, j}$ is the arithmetical mean of the normalised consumption of the foodstuff $j$ in the population group $\pi_{0}$, and $\bar{T}_{j}$ is the arithmetical mean of the available contamination data of the related food.

Under these assumptions we can also calculate the variance estimate $\hat{V}\left(E_{\pi_{0}}\right)$ using Eq. (5) and Eq. (6) in Gauchi and Leblanc (2002). We could consider this approach to be a theoretical approach, but because of the postulated assumptions, it would have to be a (very) simplified theoretical approach. For example, this simplified approach does not enable us to calculate complicated statistics such as high quantiles. Simulation methods would therefore be required to obtain estimates of these statistics. Finally, we will consider this approach to be a direct approach.

\section{Stochastic procedure to calculate the exposure: Parametric-Parametric $(P-P)$ method}

In this section we recall some elements of the methodology used to calculate the exposure by means of the stochastic procedure, already given in Gauchi and Leblanc (2002).

The main advantage of the use of a parametric method is derived from the fact that NonParametric-NonParametric method could lead us to less reliable estimations, especially of 
the high quantiles (Gauchi and Leblanc, 2002). Taking the asymmetrical appearance of consumption and contamination histograms and our previous experience into account, we fitted the probability density functions, choosing the gamma distribution to be the best candidate. Therefore, for each consumption and contamination dataset, the gamma $p d f$ was fitted with the method of maximum likelihood using the CAPABILITY procedure of SAS software (SAS 2010). The Chi-Square statistic was used in the goodness-of-fit test, considering a significance level greater than $95 \%$, to accept the distribution as a suitable candidate. Moreover, several graphical methods such as quantile-quantile plot exist, making it possible to quickly check if the fitted distribution is adapted to the selected hypothesis (Smout et al. 2000). Shape and scale parameters were estimated for each contamination set, in accordance with the methodology described above.

Concerning consumption datasets, the foodstuffs selected are commonly consumed within the Catalonian population, despite several exceptions related to age-group dietary patterns. The appearance of the histograms is therefore continuous and only one distribution was considered pooling all age groups data, fitting all data to gamma $p d f$. In case of gluten-free foods, the mean contamination was used in the simulations because few data were available.

The $P$ - $P$ method used to estimate the normalised exposure $k$ of the $S$ simulation set was built as follows:

$$
\hat{E}_{k}^{[P-P]}=\sum_{j=1}^{p} \tilde{c}_{i(j)} \tilde{t}_{j}
$$

where $\tilde{c}_{i(j)}$ is a random normalised consumption $i$ for the foodstuff $j$, drawn from $\hat{C}_{j}$, the corresponding adjusted gamma $p d f$, and $\tilde{t}_{j}$ is a random contamination for the foodstuff $j$, drawn from $\hat{T}_{j}$, the corresponding adjusted gamma $p d f$. The density parameter estimates for $\hat{C}_{j}$ and $\hat{T}_{j}$ are shown in Table $\mathrm{V}$. 
The mean of normalised exposures over the simulation set $S$ was then estimated using the following equation, where $n$ was the number of random deviates drawn $(10,000$ in the present study):

$$
\hat{E}_{S}^{[P-P]}=\frac{1}{n} \sum_{k=1}^{n} \hat{E}_{k}^{[P-P]}
$$

Other statistics were directly computed on the histogram built with the simulations of the $S$ set, and statistics were also estimated from the lognormal and gamma fitted $p d f \mathrm{~s}$.

\section{Method to build the bootstrap confidence intervals}

To know the validity and accuracy of the high quantiles estimated for the simulation method, the confidence intervals are required. Therefore, this section focuses on building bootstrap confidence intervals in order to determine the reliability of the simulation methods. Several methods to build bootstrap (Efron 1993) confidence intervals $\left(\mathrm{CI}_{b}\right)$ were assessed by Gauchi and Leblanc (2002), revealing the difficulties involved in applying the nonparametric $\mathrm{CI}_{b}$ and highlighting the "pseudo-parametric $\mathrm{CI}_{b}$ " as the best choice from among the other parametric procedures and analytical methods proposed. We therefore built $\mathrm{CI}_{b}$ according to this method. "Pseudo-parametric $\mathrm{CI}_{b}$ ", referred to as Type 1, was built by randomly drawing $B$ samples of size $n_{\pi_{0}}$ in the exposure simulation set $S$. Typically, $B$ is equal to 10,000

The boundaries of the $95 \%$ confidence interval are calculated taking the $0.025^{\text {th }}$ and $0.975^{\text {th }}$ empirical quantiles of the final bootstrap distribution.

\section{Results}

\section{Results of the Direct Approach}


The parameter estimates of this direct approach, $\hat{E}_{\pi_{0}}$ and $\hat{V}\left(E_{\pi_{0}}\right)$, for each population group are shown in Table III. They should be compared with the results of the subsequent tables. We observed that they were quite different; the infants and ethnics being the most exposed groups.

\section{Message to the editor: Place Table III approximately here (if possible).}

[Table III. Results of exposure using the direct approach.]

\section{Results of the P-P Method}

The scale and shape parameters estimated from the gamma $p d f$ fitted to consumption and contamination datasets are shown in Table IV.

\section{Message to the editor: Place Table IV approximately here (if possible).}

[Table IV. Parameters of the gamma pdf fitted to the subclasses of normalized consumption.]

Table V provides statistics calculated from the simulation outputs. The estimated statistics presented are the mean, standard deviation, skewness and kurtosis, as well as the median and the main high quantiles $\left(90^{\text {th }}, 95^{\text {th }}\right.$ and $\left.99^{\text {th }}\right)$. The highest values of skewness and kurtosis were found in the celiac sufferers group, while it was assumed that the most exposed group would be the infants and ethnics, with the highest mean and quantiles, especially the related 99th quantile. An example of exposure output histograms of relative frequencies, obtained for adult females is given in Fig. 3. When the estimated means from the simulation method are compared to those obtained through the direct approach, it is observed that they are quite higher. 
Message to the editor: Place Figure 3 and Table V approximately here (if possible).

[Fig. 3. Exposure output histograms (relative frequencies) obtained with the P-P method, for adult females. Exposure in $\mu g \mathrm{~kg}^{-1} \mathrm{bw}$ day $\left.{ }^{-1}\right]$

[Table V. Results of exposure assessment of the population groups from P-P simulation method. These results were obtained directly from the $N$ simulation outputs without pdffittings; they must be compared to the results of Table VI (in $\left.\left.\mu g \mathrm{~kg}^{-1} \mathrm{bw} d a y^{-1}\right).\right]$

Table VI shows the estimated statistics of exposure to DON by lognormal and gamma $p d f$ fitted to the outputs of the simulation method. An example of the exposure histograms is given in Fig. 4 where the fitted gamma and lognormal $p d f$ s for adolescents are given. The Anderson-Darling and Chi-Square statistics showed that lognormal and gamma distributions can be acceptable, with the exception of fitted lognormal $p d f$ for adult females and ethnics. When comparing the means from lognormal and gamma $p d f$ fittings to the simulation outputs, the values were close for all age groups with the exception of infants, the highest value of which was estimated for lognormal $p d f$ fittings. On the other hand, large differences were found for the high quantiles (95th and 99th quantiles), with the biggest values observed again for infants.

Message to the editor: Table VI approximately here (if possible).

[Table VI. Estimated statistics of exposure to DON by lognormal and gamma pdffitted to the outputs of the P-P method. See the rigorous definitions of the shape and scale parameters in the appendix. (in $\left.\mu g \mathrm{~kg}^{-1} \mathrm{bw} d a y^{-1}\right)$.]

[Fig. 4. Fitted gamma (solid line) and lognormal (broken line) pdfs for adult females. Relative parameters are given in Table VI. Exposure in $\mu \mathrm{g} \mathrm{kg}^{-1} \mathrm{bw}$ day $\mathrm{y}^{-1}$ 


\section{Results of the Bootstrap Confidence Intervals}

Confidence intervals built using the bootstrap pseudo-parametric method for the outputs of $P$ $P$ method are given in Table VII. The estimates given in Tables IV and VI were always are contained in the confidence intervals. It was therefore considered that the $P-P$ method provided reliable estimates, and that this hypothesis was valid for both those statistics estimated from lognormal and gamma $p d f$ fitted to the outputs of this simulation method.

Another point to highlight in this section is the progressive decrease in accuracy when we estimate the $\mathrm{CI}_{b}$ of high quantiles, particularly excessive in the case of the $95^{\text {th }}$ and $99^{\text {th }}$ quantiles. It is an accepted fact that it is very difficult to obtain good accuracy for the $99^{\text {th }}$ quantile, in particular (Breiman et al. 1990; Beirlant et al. 1996, 1999).

Message to the editor: Table VII approximately here (if possible).

[Table VII. Bootstrap confidence intervals obtained from the results of the P-P method. (in $\mu g$

$$
\left.\left.k g^{-1} b w d a y^{-1}\right) .\right]
$$

\section{Discussion}

In the present work the stochastic methodology developed by Gauchi and Leblanc (2002) was applied to quantify the exposure of Catalonian population to deoxynivalenol. A raw contamination data set obtained by means of thorough chemical analysis of many foodstuff samples was used. Moreover, consumption data was taken from a specific nutritional study to assess the consumption of those commodities susceptible to mycotoxin contamination, by Catalonian population. The exposure was estimated, in one hand, through a direct method, the 
most commonly method used in the previous studies, and in the other hand, by means of a simulation method $(P-P)$. Finally, the pseudo-parametric bootstrap confidence intervals were calculated for the parameters obtained through the simulation method.

In both cases, direct method and simulation method, the most exposed groups to DON were infants and ethnics. The means estimated through the simulation method were 0.15 and 0.96 $\mu \mathrm{g} \mathrm{kg}^{-1}$ bw day ${ }^{-1}$, for celiac sufferers and ethnics, respectively. The median was quite low in all cases (0.04-0.36 $\mathrm{g} \mathrm{kg}^{-1}$ bw day $\left.{ }^{-1}\right)$, but the high percentiles increased these estimated intakes until worrying values, for example $3.82 \mu \mathrm{g} \mathrm{kg}^{-1}$ bw day ${ }^{-1}$ (percentile 95 for ethnic group). When the estimates were compared to the TDI of $1 \mu \mathrm{g} \mathrm{kg}^{-1}$ body weight (SCF 2002), it was observed that the mean values were between $15 \%$ and $96 \%$ of TDI, and the high percentiles commonly exceeded it.

Other studies have already estimated a high DON consumption worldwide, for example, JECFA estimated human dietary intake of DON in five regional diets, the highest one occurring in the Middle Eastern region $\left(2.4 \mu \mathrm{g} \mathrm{kg}^{-1}\right.$ bw day $\left.{ }^{-1}\right)$, followed by Far Eastern and European (1.6 and $1.4 \mu \mathrm{g} \mathrm{kg}^{-1} \mathrm{bw} \mathrm{day}^{-1}$, respectively) (Canady et al. 2001). In the First French Total Diet Study, Leblanc et al. (2005) estimated DON daily intakes of 0.28 and $0.57 \mu \mathrm{g} \mathrm{kg}^{-1}$ bw day ${ }^{-1}$, for mean and percentile 95 for adults, respectively; while 0.45 and $0.93 \mu \mathrm{g} \mathrm{kg}^{-1}$ bw day $^{-1}$, were estimated for children. A probabilistic methodology to assess the exposure to DON was conducted in Netherlands, concluding that 1-year-old children was the most exposed group, with estimated intakes of 0.46 and $1.00 \mu \mathrm{g} \mathrm{kg}^{-1} \mathrm{bw} \mathrm{day}{ }^{-1}$, for the median and percentile 95, respectively (Pieters et al. 2004).

To our knowledge, this is the first study to assess the exposure of special population groups to deoxynivalenol. The special groups selected in the present study had dietary habits markedly different from the general population. In one hand, celiac sufferers substitute the wheat-based food for other gluten free cereals, and in the other hand, some ethnic groups partially maintain 


\section{Acknowledgements}

The authors would like to acknowledge Exposure Assessment of Spanish Population to Fusarium Toxins Project, National Plan of Spanish Government (AGL2008-05030-C02-01), Catalonian Food Safety Agency of 'Generalitat de Catalunya' Health Department and University of Lleida for their financial support, and to Mathematics and Informatics Applied Group, INRA (Jouy-en-Josas center), for their technical support.

\section{Appendix: Definitions of the lognormal and gamma probability density functions}

The lognormal $p d f$ for the continuous random variable $Y$ defined in $[0,+\infty[$ is:

$$
g(y)=\frac{1}{\sqrt{2 \pi} y \sigma_{X}} \exp \left(-\frac{1}{2}\left(\frac{\log (y)-m_{X}}{\sigma_{x}}\right)^{2}\right)
$$


where $m_{X}$ and $\sigma_{X}$ are $\lambda$ and $r$, the scale and the shape parameters, respectively. $X$ then follows a normal distribution with mean $m_{X}$ and variance $\sigma_{X}^{2}$. The mean and the variance of $Y$ are defined by $E(Y)=\exp \left(m_{X}+\sigma_{X}^{2} / 2\right)$ and $V(Y)=\left[\exp \left(2 m_{X}+\sigma_{X}^{2}\right)\right]\left[\exp \left(\sigma_{X}^{2}\right)-1\right]$, respectively.

The gamma $p d f$ for a continuous random variable $X$ defined in $[0,+\infty[$ is:

$$
f(x)=\frac{1}{\lambda \Gamma(r)}\left(\frac{x-\theta}{\lambda}\right)^{r-1} \exp \left(-\frac{x-\theta}{\lambda}\right)
$$

where $\mathrm{r}, \lambda$ and $\theta$ are the shape, scale, and the threshold parameters, respectively, and $\Gamma(r)$ is the usual Euler's integral. The mean and variance of the gamma distribution are related to $r$ and $\lambda$ in the following way: $E(X)=r \lambda$ and $V(X)=r \lambda^{2}$.

\section{References}

Beirlant J, Teugels JL, Vynckier P. 1996. Practical analysis of extreme values. Leuven: University Press.

Beirlant J, Devroye L. 1999. On the impossibility of estimating densities in the extreme tail. Stat Prob Lett. 43:57-64.

Breiman L, Stone CJ, Kooperberg C. 1990. Robust confidence bounds for extreme upper quantiles. J Stat Comp Simul. 37:127-149.

Canady RA, Coker RD, Rgan SK, Krska R, Kuiper-Goodman T, Olsen M, Pestka JJ, Resnik S, Schlatter J. 2001. Deoxynivalenol. Safety Evaluation of Certain Mycotoxins in Food. FiftySixth Report of the Joint FAO/WHO Expert Committee on Food Additives. International Programme on Chemical Safety, World Health Organization, Geneva, p. 420-555. 
Gauchi J-P, Leblanc J-C. 2002. Quantitative assessment of exposure to the mycotoxin Ochratoxin A in food. RiskAnal 22:219-34.

Global Environment Monitoring System/Food- World Health Organization (GEMs/FoodWHO),,Reliable evaluation of low-level contamination of food-workshop in the frame of GEMS/Food-EURO [Internet]. 1995. Kulmbach, Germany: GEMs/Food-WHO. [cited 2009 $\begin{array}{llll}\text { May } & 01] & \text { Available }\end{array}$ http://www.who.int/foodsafety/publications/chem/lowlevel_may1995/en/index.html

Hazel CM, Patel S. 2004. Influence of processing on trichothecene levels. Toxicol Lett $153: 51-59$.

Iman RL, Conover WJ. 1982. A distribution-free approach to inducing rank correlation among input variables. Comm Statist Simul Comput 11:311-34. 
Jelinek CF, Pohland AE, Wood GE. 1989. Worldwide occurrence of mycotoxins in foods and feeds-an update. Journal AOAC 72:223-230.

Joint FAO/WHO Expert Committee on Food Additives (JECFA). 2001. Safety Evaluation of Certain Mycotoxins in Food. Rome, Italy: Food and Agriculture Organization; p. 281-320.

Kroes R, Müller D, Lambe J, Löwik MRH, Van Klaveren J, Kleiner J, Massey R, Mayer S, Urieta I, Verger P. 2002. Visconti A. Assessment of intake from the diet. Food Chem. Toxicol. 40:327-85.

Migracat (Observatori de la Imigracio a Catalunya) [Internet] [Cited 2010 Aug 5] Available from: http://www.gencat.cat/dasc/publica/butlletiIMMI/xifres6/index.htm.

Rotter BA, Prelusky DB, Pestka JJ. 1996. Toxicology of deoxynivalenol (vomitoxin). J Toxicol Environ Health - A. 48:1-34.

Leblanc J, Tard A, Volatier J, Verger P. 2005. Estimated dietary exposure to principal food mycotoxins from The First French Total Diet Study. Food Addit Contam. 22:652-72.

Pieters MN, Bakker M, Slob W. 2004. Reduced intake of deoxynivalenol in the Netherlands: A risk assessment update. Toxicol Lett. 153:145-153.

SAS Institute. 2010. North Carolina, USA. 
Scientific Committee on Food (SCF). Opinion on Fusarium toxins-Part 6: Group evaluation of T-2 toxin, HT-2 toxin, nivalenol and deoxynivalenol [Internet]. 26 February 2002. [Cited 2010 Feb 15]. Available from: http://europa.eu.int/comm/food/fs/sc/scf/out123 en.pdf.

SCOOP (Scientific Cooperation Task 3.2.10 of the European Commission). 2003. Collection of occurrence data of Fusarium toxins in food and assessment of dietary intake by the population of EU Member States. Final report. Directorate - General Health and Consumer Protection. Brussels, Belgium: European Commission.

Scott PM. 1989. Trichothecene Mycotoxicosis: Pathophysiologic Effects. Boca Raton: CRC Press. The natural occurrence of trichothecenes; p. 1-26.

Serra-Majem L, Ribas L, Salvador G, Castells C, Serra J, Jover L. 2003. Avaluació de l'estat nutricional de la població catalana 2002-2003. Evolució dels hàbits alimentaris i del consum d'aliments i nutrients a Catalunya (1992-2003). Barcelona, Spain: Direcció General de Salut Pública, Departament de Sanitat i Seguretat Social, Generalitat de Catalunya.

Smout C, Van Loey A, Hendrickx M, Beirlant J. 2000. Statistical variability of heat penetration parameters in relation to process design. J Food Sci. 65:685-93.

University of Lleida - Catalonian Food Security Agency (UdL-ACSA). 2010. Project to Assess the Exposure of Catalonian Population to the Mycotoxins. 2n Internal Technical Report Aug 2010. Lleida. Applied Microbiology Group/ Food Technology Department/ University of Lleida. Supported by Catalonian Food Security Agency. 
Verger P, Fabiansson S. 2008. Recent progress in exposure assessment and its interaction with the risk analysis process. Trends Food Sci Technol. 19:92-8.

World Health Organization (WHO). 2005. Dietary exposure assessment of chemicals in food. Report of a joint FAO/WHO consultation, Annapolis, Maryland, USA. 
Table I. Occurrence of deoxynivalenol in food products available in the Catalonian market.

\begin{tabular}{|c|c|c|c|c|c|}
\hline & $\underset{\text { individual }}{\mathbf{N}}$ & $\underset{\text { composite }}{\mathrm{N}}$ & Samples >LOQ & $\begin{array}{c}\text { Mean } \pm s d \\
\mu \mathrm{g} / \mathrm{g}\end{array}$ & $\begin{array}{l}\operatorname{Max} \\
\mu \mathrm{g} / \mathrm{g}\end{array}$ \\
\hline Wheat flakes $^{l}$ & 27 & 27 & $20 / 27$ & $0.190 \pm 0.117$ & 0.437 \\
\hline Corn flakes ${ }^{l}$ & 168 & 65 & $49 / 65$ & $0.109 \pm 0.078$ & 0.580 \\
\hline Beer $^{l}$ & 213 & 71 & $1 / 70$ & 0.012 & 0.012 \\
\hline Sweet corn ${ }^{l}$ & 185 & 72 & $2 / 72$ & $0.114 \pm 0.036$ & 0.139 \\
\hline Corn snacks ${ }^{l}$ & 213 & 71 & $56 / 71$ & $0.153 \pm 0.058$ & 0.304 \\
\hline Pasta $^{l}$ & 201 & 70 & $52 / 70$ & $0.226 \pm 0.177$ & 0.946 \\
\hline Sliced bread ${ }^{l}$ & 147 & 72 & $12 / 72$ & $0.068 \pm 0.018$ & 0.098 \\
\hline Bread $^{l}$ & 31 & 31 & $31 / 31$ & $0.246 \pm 0.158$ & 0.739 \\
\hline Ethnic foods ${ }^{2}$ & 35 & 35 & $20 / 35$ & $0.406 \pm 0.272$ & 1.080 \\
\hline $\begin{array}{l}\text { Gluten-free } \\
\text { Bread }^{2}\end{array}$ & 5 & 5 & $1 / 5$ & 0.270 & 0.270 \\
\hline Gluten-free pasta ${ }^{2}$ & 7 & 7 & $1 / 7$ & 0.163 & 0.163 \\
\hline Baby food ${ }^{x}$ & 30 & 30 & $12 / 30$ & $0.131 \pm 0.054$ & 0.286 \\
\hline
\end{tabular}


Table II. Normalised consumption of the main foodstuffs related to DON contamination by the 384 adult females ( $\mathrm{g} / \mathrm{kg}$ body weight/day).

\begin{tabular}{lccccc} 
& \multicolumn{3}{c}{$\%$} & & \\
& Consumers & Consumers & Mean & $S D$ & Max \\
\hline Breakfast cereals & 153 & 39.8 & 0.48 & 0.46 & 2.35 \\
Sliced Bread & 161 & 41.9 & 0.22 & 0.32 & 1.74 \\
Bread & 365 & 95.1 & 0.91 & 0.72 & 4.78 \\
Pasta & 378 & 98.4 & 0.34 & 0.29 & 3.51 \\
Corn Snacks & 114 & 29.7 & 0.07 & 0.11 & 0.91 \\
Beer & 204 & 53.1 & 1.43 & 1.97 & 10.14 \\
Sweet Corn & 143 & 37.2 & 0.50 & 1.08 & 8.33 \\
\hline
\end{tabular}


1

2

3

4

5

6

7

8

9

10

11

12

13

14

15

16

17

18

19

20

21

22

23

24

25

26

27

28

29

30

31

32

33

34

35

36

37

38

39

40

41

42

43

44

45

46

47

48

49

50

51

52

53

54

55

56

57

58

59

60

Table III. Results of exposure using the direct approach.

\begin{tabular}{lcc} 
& $\hat{E}_{\pi_{0}}$ & $\hat{V}\left(E_{\pi_{0}}\right)$ \\
\hline Seniors & 0.04 & $(0.04)^{2}$ \\
Celiac sufferers & 0.13 & $(0.09)^{2}$ \\
Ethnics & 0.57 & $(0.47)^{2}$ \\
Adults females & 0.09 & $(0.07)^{2}$ \\
Adults males & 0.10 & $(0.08)^{2}$ \\
Adolescents & 0.15 & $(0.13)^{2}$ \\
Children & 0.36 & $(0.27)^{2}$ \\
Infants & 0.74 & $(0.71)^{2}$ \\
\hline$\left(\mu \mathrm{g} \mathrm{kg}^{-1} \mathrm{bw} \mathrm{day}^{-1}\right)$ & &
\end{tabular}


Table IV. Parameters of the gamma $p d f$ fitted to the subclasses of normalized consumption.

\begin{tabular}{|c|c|c|c|c|}
\hline Foodstuff $^{a}$ & Elders $(\hat{r}, \hat{\lambda})$ & Adult females $(\hat{r}, \hat{\lambda})$ & Adult males $(\hat{r}, \hat{\lambda})$ & Teenagers $(\hat{r}, \hat{\lambda})$ \\
\hline $\begin{array}{c}\text { Breakfast cereals } \\
(0.457 ; 1.437)\end{array}$ & not enough data & $0.895 ; 0.542$ & $1.229 ; 0.354$ & $0.873 ; 0.891$ \\
\hline $\begin{array}{c}\text { Bread } \\
(0.458 ; 1.436)\end{array}$ & $1.999 ; 0.381$ & $0.765 ; 1.089$ & $0.705 ; 1.701$ & $0.554 ; 2.218$ \\
\hline $\begin{array}{l}\text { Sliced bread } \\
(0.824 ; 52.632)\end{array}$ & $2.840 ; 0.0384$ & $0.762 ; 0.294$ & $0.611 ; 0.624$ & $0.674 ; 0.785$ \\
\hline $\begin{array}{c}\text { Pasta } \\
(0.747 ; 4.386)\end{array}$ & $1.423 ; 0.1616$ & $2.263 ; 0.151$ & $2.149 ; 0.195$ & $1.770 ; 0.292$ \\
\hline $\begin{array}{c}\text { Corn snacks } \\
(1.410 ; 11.364)\end{array}$ & not enough data & $0.635 ; 0.787$ & $1.396 ; 0.044$ & $0.790 ; 0.211$ \\
\hline $\begin{array}{c}\text { Beer } \\
\text { (not enough data) }\end{array}$ & $0.606 ; 3.039$ & $0.735 ; 1.945$ & $0.937 ; 2.471$ & $0.759 ; 1.532$ \\
\hline $\begin{array}{c}\text { Sweet corn } \\
\text { (not enough data) }\end{array}$ & not enough data & $0.635 ; 0.787$ & $0.777 ; 0.475$ & $0.653 ; 0.543$ \\
\hline $\begin{array}{l}\text { Ethnic foods } \\
(0.892 ; 0.535)\end{array}$ & 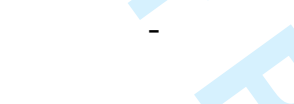 & - & - & - \\
\hline $\begin{array}{c}\text { Baby food } \\
(0.458 ; 1.436)\end{array}$ & - & - & - & - \\
\hline Foodstuff $^{\mathrm{a}}$ & Infants $(\hat{r}, \hat{\lambda})$ & $\operatorname{Babies}(\hat{r}, \hat{\lambda})$ & Ethnics $(\hat{r}, \hat{\lambda})$ & Celiacs $(\hat{r}, \hat{\lambda})$ \\
\hline $\begin{array}{c}\text { Breakfast cereals } \\
(0.457 ; 1.437)\end{array}$ & $1.106 ; 1.772$ & $2-$ & $0.130 ; 1.739$ & $0.193 ; 2.020$ \\
\hline $\begin{array}{c}\text { Bread } \\
(0.458 ; 1.436)\end{array}$ & $0.741 ; 5.707$ & & $0.892 ; 1.869$ & $0.550 ; 2.096$ \\
\hline $\begin{array}{l}\text { Sliced bread } \\
(0.824 ; 52.632)\end{array}$ & $0.853 ; 1.102$ & - & not enough data & not enough data \\
\hline $\begin{array}{c}\text { Pasta } \\
(0.747 ; 4.386)\end{array}$ & $2.256 ; 0.449$ & - & $1.231 ; 0.242$ & $0.786 ; 0.236$ \\
\hline $\begin{array}{l}\text { Corn snacks } \\
(1.410 ; 11.364)\end{array}$ & $1.074 ; 0.212$ & - & $0.152 ; 0.716$ & $0.258 ; 0.272$ \\
\hline $\begin{array}{c}\text { Beer } \\
\text { (not enough data) }\end{array}$ & 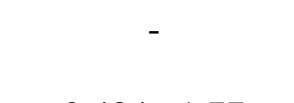 & - & $0.157 ; 14.485$ & $0.133 ; 2.413$ \\
\hline $\begin{array}{c}\text { Sweet corn } \\
\text { (not enough data) }\end{array}$ & $0.484 ; 1.77$ & - & $0.140 ; 0.461$ & $0.167 ; 0.908$ \\
\hline $\begin{array}{l}\text { Ethnic foods } \\
(0.892 ; 0.535)\end{array}$ & - & - & $0.295 ; 1.297$ & - \\
\hline $\begin{array}{c}\text { Baby food } \\
(0.458 ; 1.436)\end{array}$ & - & $1.474 ; 10.579$ & - & - \\
\hline
\end{tabular}


1

2

3
Table V. Results of exposure assessment of the population groups from $P-P$ simulation method. These results were obtained directly from the $\mathrm{N}$ simulation outputs without $p d f$ fittings; they must be compared to the results of Table VI (in $\mu \mathrm{g} \mathrm{kg}^{-1}$ bw day ${ }^{-1}$ ).

\section{P-P Method}

\begin{tabular}{|c|c|c|c|}
\hline & Seniors & Adult females & Adult males \\
\hline $\mathrm{N}$ & 10000 & 10000 & 10000 \\
\hline Mean & 0.28 & 0.56 & 0.37 \\
\hline SD & 0.48 & 0.77 & 0.48 \\
\hline Skewness & 5.58 & 4.97 & 4.79 \\
\hline Kurtosis & 59.47 & 41.65 & 41.08 \\
\hline Median & 0.12 & 0.32 & 0.22 \\
\hline $0.90^{\text {th }}$ quantile & 0.71 & 1.26 & 0.82 \\
\hline $0.95^{\text {th }}$ quantile & 1.08 & 1.84 & 1.18 \\
\hline \multirow[t]{2}{*}{$0.99^{\text {th }}$ quantile } & 2.27 & 3.70 & 2.33 \\
\hline & Adolescents & Children & Infants \\
\hline $\mathrm{N}$ & 10000 & 10000 & 10000 \\
\hline Mean & 0.43 & 0.68 & 0.90 \\
\hline SD & 0.55 & 1.83 & 1.51 \\
\hline Skewness & 3.26 & 10.16 & 4.80 \\
\hline Kurtosis & 14.39 & 156.74 & 42.15 \\
\hline Median & 0.25 & 0.24 & 0.36 \\
\hline $0.90^{\text {th }}$ quantile & 0.99 & 1.38 & 2.33 \\
\hline $0.95^{\text {th }}$ quantile & 1.46 & 2.49 & 3.57 \\
\hline \multirow[t]{2}{*}{$0.99^{\text {th }}$ quantile } & 2.86 & 8.17 & 7.15 \\
\hline & Ethnics & Celiac sufferers & \\
\hline $\mathrm{N}$ & 10000 & 10000 & \\
\hline Mean & 0.96 & 0.15 & \\
\hline SD & 1.98 & 0.55 & \\
\hline Skewness & 6.95 & 19.20 & \\
\hline Kurtosis & 79.96 & 724.87 & \\
\hline Median & 0.36 & 0.04 & \\
\hline $0.90^{\text {th }}$ quantile & 2.24 & 0.29 & \\
\hline $0.95^{\text {th }}$ quantile & 3.82 & 0.64 & \\
\hline $0.99^{\text {th }}$ quantile & 9.38 & 2.18 & \\
\hline
\end{tabular}


Table VI. Estimated statistics of exposure to DON by lognormal and gamma $p d f$ fitted to the outputs of the $P-P$ method. See the rigorous definitions of the shape and scale parameters in the appendix. (in $\mu \mathrm{g} \mathrm{kg}^{-1}$ bw day ${ }^{-1}$ ).

\section{$P$-P Method}

\begin{tabular}{lccc} 
& Seniors & Adult Females & Adult Males \\
\hline Lognormal & $\hat{r}=\mathbf{1 . 6 1 4} ; \quad \hat{\lambda}=-\mathbf{2 . 3 0 2}$ & $\hat{r}=\mathbf{1 . 0 6 1 ;} \quad \hat{\lambda}=-\mathbf{1 . 1 4 6}$ & $\hat{r}=\mathbf{1 . 0 3 6 ;} \hat{\lambda}=-\mathbf{1 . 5 2 6}$ \\
Mean & 0.37 & 0.56 & 0.37 \\
$\mathrm{SD}$ & 1.30 & 0.80 & 0.52 \\
Median & 0.10 & 0.32 & 0.22 \\
$0.90^{\text {th }}$ quantile & 0.79 & 1.24 & 0.82 \\
$0.95^{\text {th }}$ quantile & 1.42 & 1.82 & 1.19 \\
$0.99^{\text {th }}$ quantile & 4.27 & 3.75 & 2.42
\end{tabular}

\begin{tabular}{lccc} 
AD (p-value $)$ & $31.88(<0.005)$ & $0.25(>0.5)$ & $0.79(<0.042)$ \\
\hline Gamma & $\hat{r}=\mathbf{0 . 6 0 7} ; \hat{\lambda}=\mathbf{0 . 4 5 6}$ & $\hat{r}=\mathbf{1 . 0 2 7} ; \hat{\lambda}=\mathbf{0 . 5 4 2}$ & $\hat{r}=\mathbf{1 . 0 8 3 ;} \hat{\lambda}=\mathbf{0 . 3 4 0}$ \\
Mean & 0.28 & 0.56 & 0.37 \\
$\mathrm{SD}$ & 0.36 & 0.55 & 0.35 \\
Median & 0.15 & 0.39 & 0.26 \\
$0.90^{\text {th }}$ quantile & 0.72 & 1.27 & 0.83 \\
$0.95^{\text {th }}$ quantile & 0.99 & 1.65 & 1.07 \\
$0.99^{\text {th }}$ quantile & 1.65 & 2.53 & 1.63
\end{tabular}

\begin{tabular}{lccc} 
Chi-Sq (p-value) & $15402.96(<0.001)$ & $133.80(<0.001)$ & $108.08(<0.001)$ \\
\hline Lognormal & Adolescents & Children & Infants \\
Mean & $\hat{r}=\mathbf{1 . 0 6 6 ;} \quad \hat{\lambda}=-1.389$ & $\hat{r}=1.397 ; \quad \hat{\lambda}=-1.439$ & $\hat{r}=\mathbf{1 . 8 4 1 ;} \hat{\lambda}=-\mathbf{1 . 2 4 0}$ \\
SD & 0.44 & 0.63 & 1.58 \\
Median & 0.64 & 1.55 & 8.44 \\
$0.90^{\text {th }}$ quantile & 0.25 & 0.24 & 0.29 \\
$0.95^{\text {th }}$ quantile & 0.98 & 1.42 & 3.06 \\
$0.99^{\text {th }}$ quantile & 1.44 & 2.36 & 5.98 \\
(.) & 2.98 & 6.12 & 20.98
\end{tabular}

\begin{tabular}{lccc}
$\mathrm{AD}(\mathrm{p}$-value $)$ & $4.37(<0.005)$ & $3.79(<0.005)$ & $80.97(<0.005)$ \\
\hline Gamma & $\hat{r}=\mathbf{1 . 0 3 9} ; \hat{\lambda}=\mathbf{0 . 4 1 7}$ & $\hat{r}=\mathbf{0 . 5 9 1 ;} \hat{\lambda}=-\mathbf{1 . 1 4 6}$ & $\hat{r}=\mathbf{0 . 5 5 0 ;} \hat{\lambda}=\mathbf{1 . 6 4 4}$ \\
Mean & 0.43 & 0.68 & 0.90 \\
$\mathrm{SD}$ & 0.43 & 0.88 & 1.22 \\
Median & 0.31 & 0.35 & 0.45 \\
$0.90^{\text {th }}$ quantile & 0.99 & 1.77 & 2.40 \\
$0.95^{\text {th }}$ quantile & 1.28 & 2.45 & 3.36 \\
$0.99^{\text {th }}$ quantile & 0.96 & 4.10 & 5.69 \\
Chi-Sq (p-value $)$ & $1239.06(<0.001)$ & $190006.68(<0.001)$ & $14077.63(<0.001)$
\end{tabular}

AD: Anderson Darling statistic; Chi-Sq: Chi Square statistic 


\begin{tabular}{lcc} 
& Ethnics & Celiacs \\
\hline Lognormal & $\hat{r}=\mathbf{1 . 4 3 4 ;} \hat{\lambda}=-\mathbf{1 . 0 8 8}$ & $\hat{r}=\mathbf{1 . 3 7 4 ;} \hat{\lambda}=-\mathbf{3 . 0 8 9}$ \\
Mean & 1.00 & 0.12 \\
$\mathrm{SD}$ & 2.61 & 0.28 \\
Median & 0.36 & 0.05 \\
$0.90^{\text {th }}$ quantile & 2.25 & 0.27 \\
$0.95^{\text {th }}$ quantile & 3.78 & 0.44 \\
$0.99^{\text {th }}$ quantile & 10.06 & 1.11 \\
$\mathrm{AD}$ (p-value) & $0.46(0.267)$ & $66.40(<0.005)$ \\
\hline Gamma & $\hat{r}=\mathbf{0 . 6 2 2} ; \hat{\lambda}=\mathbf{1 . 5 4 6}$ & $\hat{r}=\mathbf{0 . 5 1 7} ; \hat{\lambda}=\mathbf{0 . 2 9 9}$ \\
Mean & 0.96 & 0.16 \\
$\mathrm{SD}$ & 1.22 & 0.22 \\
Median & 0.52 & 0.07 \\
$0.90^{\text {th }}$ quantile & 2.48 & 0.42 \\
$0.95^{\text {th }}$ quantile & 3.51 & 0.59 \\
$0.99^{\text {th }}$ quantile & 5.67 & 1.01 \\
Chi-Sq (p-value $)$ & $52310.98(<0.001)$ & $154786.81(<0.001)$
\end{tabular}


Table VII. Bootstrap confidence intervals obtained from the results of the P-P method. (in $\mu \mathrm{g} \mathrm{kg}^{-1}$ bw day ${ }^{-1}$ ).

P-P Method 95\% Bootstrap Confidence Interval

\begin{tabular}{|c|c|c|c|}
\hline & Seniors & Adult Females & Adult Males \\
\hline Mean & {$[0.19 ; 0.40]$} & {$[0.48 ; 0.64]$} & {$[0.32 ; 0.42]$} \\
\hline SD & {$[0.24 ; 0.88]$} & {$[0.55 ; 1.05]$} & {$[0.35 ; 0.66]$} \\
\hline Median & {$[0.07 ; 0.18]$} & {$[0.27 ; 0.36]$} & {$[0.19 ; 0.25]$} \\
\hline $0.90^{\text {th }}$ quantile & {$[0.43 ; 1.12]$} & {$[1.03 ; 1.47]$} & {$[0.68 ; 0.98]$} \\
\hline $0.95^{\text {th }}$ quantile & {$[0.66 ; 1.95]$} & {$[1.43 ; 2.26]$} & {$[0.94 ; 1.45]$} \\
\hline \multirow[t]{2}{*}{$0.99^{\text {th }}$ quantile } & {$[1.11 ; 6.51]$} & {$[2.60 ; 5.89]$} & {$[1.61 ; 3.46]$} \\
\hline & Adolescents & Children & Infants \\
\hline Mean & {$[0.37 ; 0.51]$} & {$[0.37 ; 1.23]$} & {$[0.67 ; 1.19]$} \\
\hline SD & {$[0.41 ; 0.70]$} & {$[0.48 ; 4.47]$} & {$[0.93 ; 2.56]$} \\
\hline Median & {$[0.21 ; 0.29]$} & {$[0.16 ; 0.35]$} & {$[0.25 ; 0.53]$} \\
\hline $0.90^{\text {th }}$ quantile & {$[0.80 ; 1.28]$} & {$[0.80 ; 2.86]$} & {$[1.62 ; 3.21]$} \\
\hline $0.95^{\text {th }}$ quantile & {$[1.12 ; 1.98]$} & {$[1.16 ; 5.60]$} & {$[2.40 ; 5.46]$} \\
\hline \multirow[t]{2}{*}{$0.99^{\text {th }}$ quantile } & {$[1.88 ; 3.99]$} & {$[2.41 ; 36.42]$} & {$[3.95 ; 12.29]$} \\
\hline & Ethnics & Celiacs & \\
\hline Mean & {$[0.56 ; 1.58]$} & {$[0.07 ; 0.33]$} & \\
\hline $\mathrm{SD}$ & {$[0.70 ; 4.09]$} & {$[0.10 ; 1.21]$} & \\
\hline Median & {$[0.22 ; 0.55]$} & {$[0.03 ; 0.06]$} & \\
\hline $0.90^{\text {th }}$ quantile & {$[1.23 ; 4.33]$} & {$[0.12 ; 0.81]$} & \\
\hline $0.95^{\text {th }}$ quantile & {$[1.89 ; 8.79]$} & {$[0.22 ; 2.07]$} & \\
\hline $0.99^{\text {th }}$ quantile & {$[3.21 ; 28.40]$} & {$[0.50 ; 8.23]$} & \\
\hline
\end{tabular}



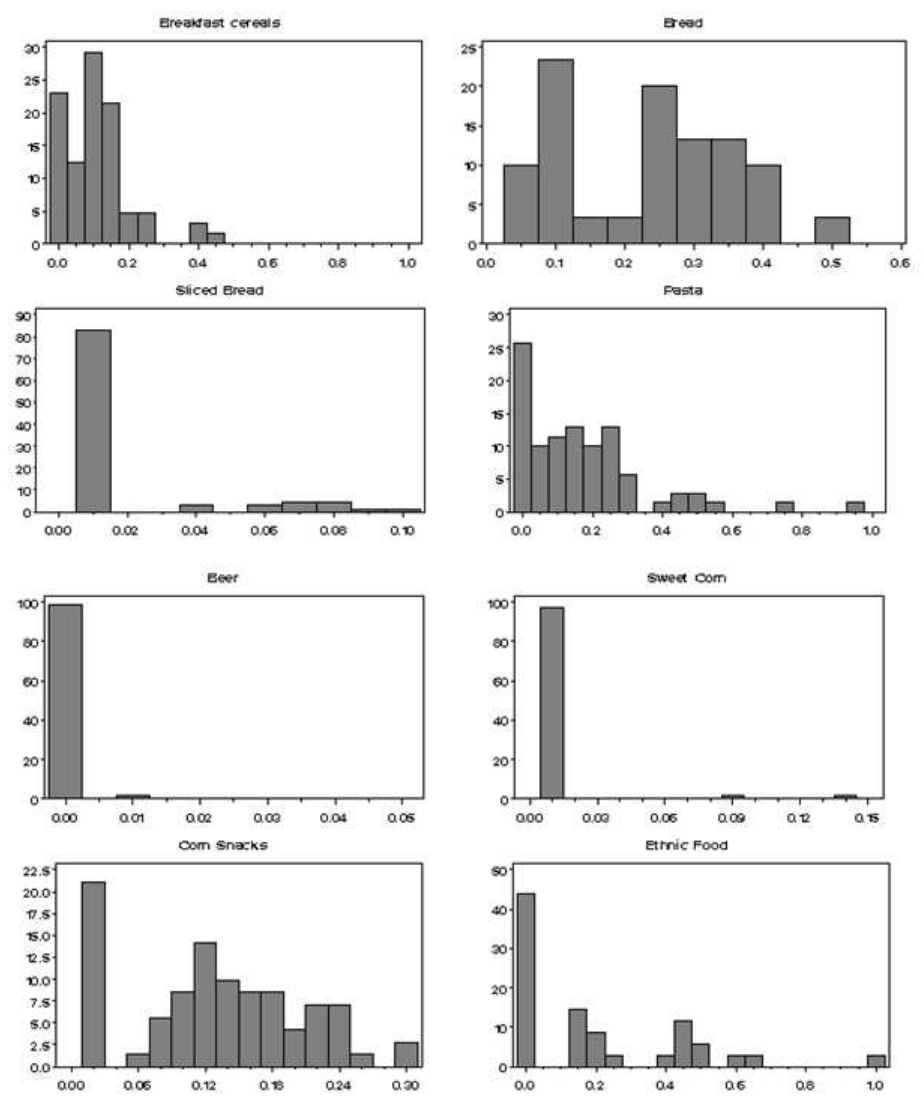

Fig 1. Contamination histograms (relative frequencies), in $\mu \mathrm{g} \mathrm{g-1}$ for each food $190 \times 275 \mathrm{~mm}(96 \times 96 \mathrm{DPI})$ 

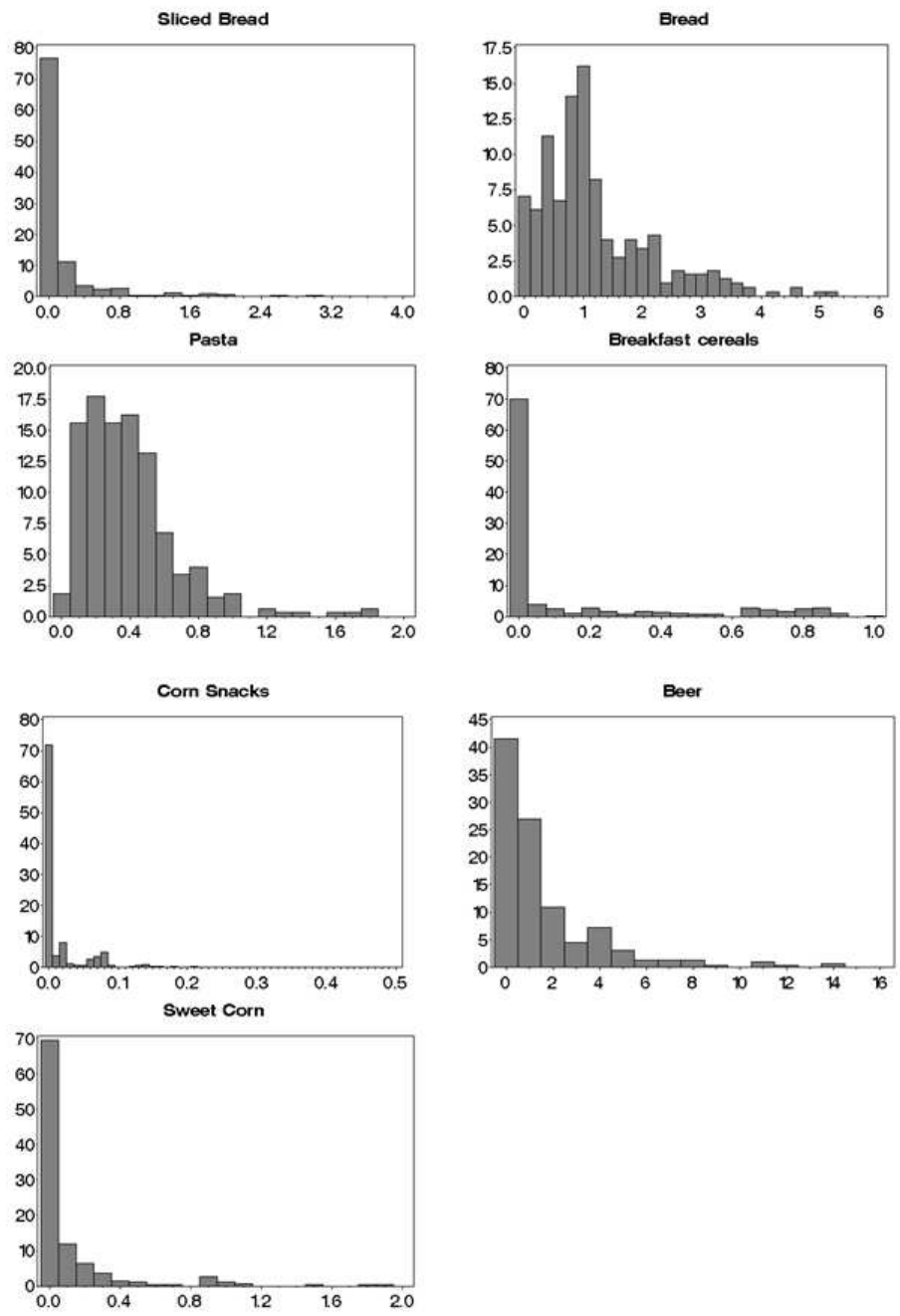

Fig 2. Consumption histograms (relative frequencies) for adult female consumers, in $\mu \mathrm{gg}-1 \mathrm{bw}$ day-1. $190 \times 275 \mathrm{~mm}(96 \times 96 \mathrm{DPI})$ 


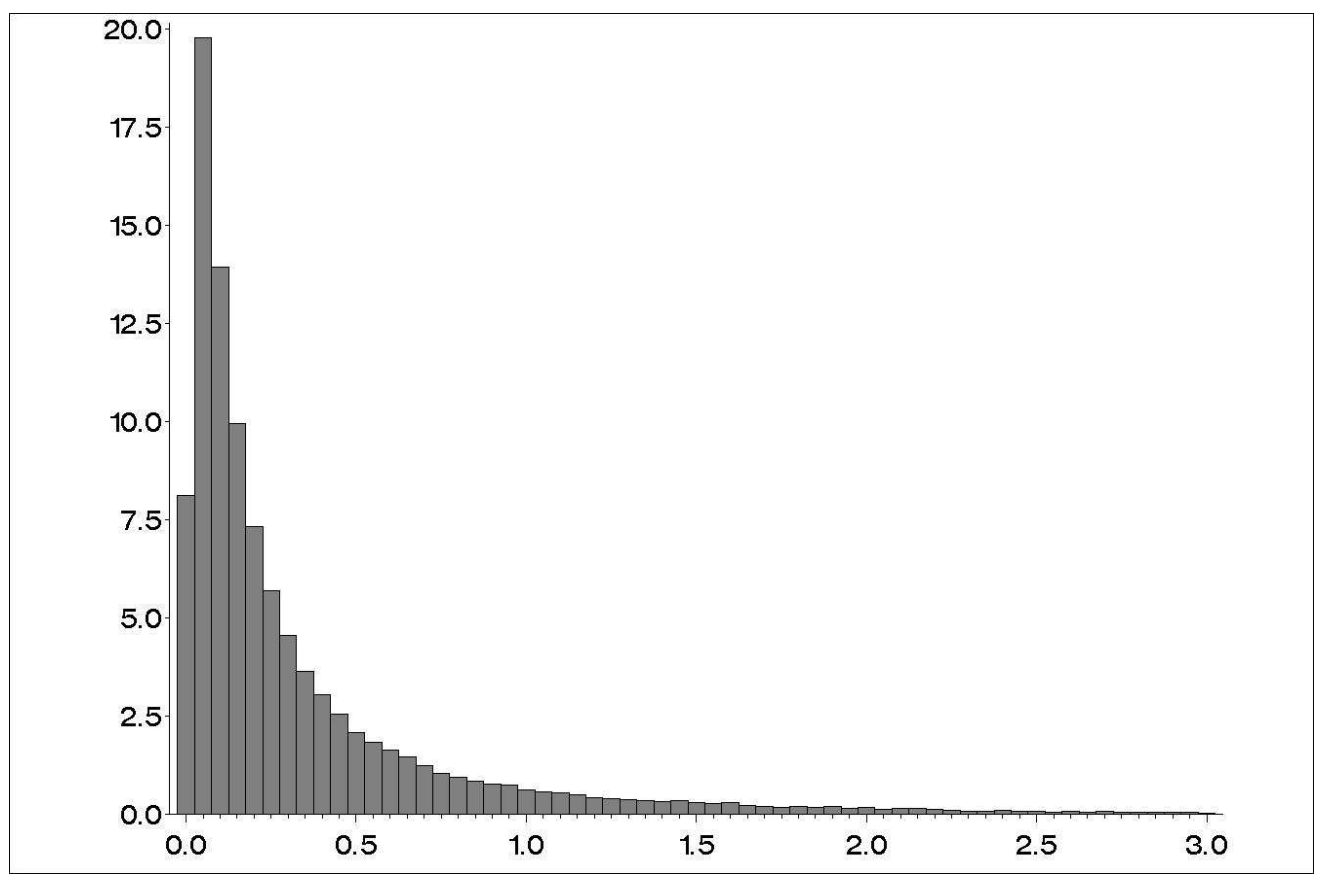

Fig. 3. Exposure output histograms (relative frequencies) obtained with the P-P method, for adult females. Exposure in $\mu \mathrm{g} \mathrm{kg-1}$ bw day-1.

$$
354 \times 234 \mathrm{~mm}(96 \times 96 \mathrm{DPI})
$$




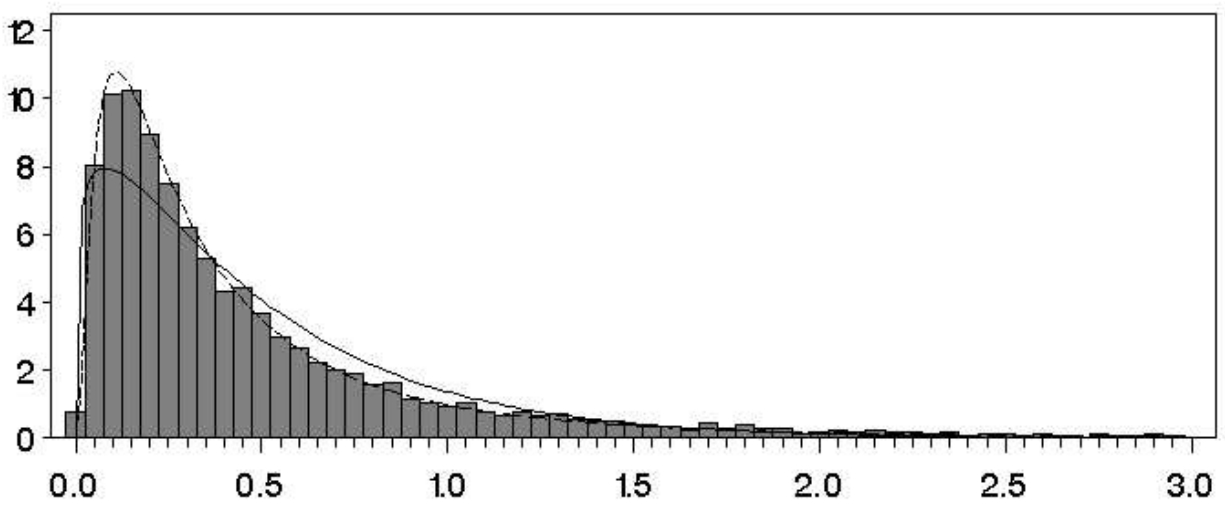

Fig. 4. Fitted gamma (solid line) and lognormal (broken line) pdfs for adult females. Relative parameters are given in Table VI. Exposure in $\mu \mathrm{g} \mathrm{kg-1}$ bw day-1. $181 \times 83 \mathrm{~mm}(100 \times 100 \mathrm{DPI})$ 


\section{Tables Captions}

Table I. Occurrence of deoxynivalenol in food matrices from food available on the Catalonian market.

Table II. Normalised consumption of the main foodstuff related to DON contamination by the 384 adult females $\left(\mathrm{g} \mathrm{kg}^{-1}\right.$ body weight $\left.\mathrm{day}^{-1}\right)$.

Table III. Results of exposure using the direct approach.

Table IV. Parameters of the gamma pdf fitted to the subclasses of normalized consumption.

Table V. Results of exposure assessment of the population groups from P-P simulation method. These results were obtained directly from the $\mathrm{N}$ simulation outputs without pdf fittings; they must be compared to the results of Table VI (in $\mu \mathrm{g} \mathrm{kg}^{-1}$ bw day ${ }^{-1}$ ).

Table VI. Estimated statistics of exposure to DON by lognormal and gamma pdf fitted to the outputs of the P-P method. See the rigorous definitions of the shape and scale parameters in the appendix. (in $\mu \mathrm{g} \mathrm{kg}^{-1}$ bw day ${ }^{-1}$ ).

Table VII. Bootstrap confidence intervals obtained from the results of the P-P method. (in $\mu \mathrm{g}$ $\mathrm{kg}^{-1}$ bw day ${ }^{-1}$.

\section{Figures Captions}

Fig 1. Contamination histograms (relative frequencies), in $\mu \mathrm{g} \mathrm{g}{ }^{-1}$ for each food

Fig 2. Consumption histograms (relative frequencies) for adult female consumers, in $\mu \mathrm{g} \mathrm{kg}^{-1}$ bw day ${ }^{-1}$.

Fig. 3. Exposure output histograms (relative frequencies) obtained with the P-P method, for adult females. Exposure in $\mu \mathrm{g} \mathrm{kg}^{-1}$ bw day ${ }^{-1}$.

Fig. 4. Fitted gamma (solid line) and lognormal (broken line) pdfs for adult females. Relative parameters are given in Table VI. Exposure in $\mu \mathrm{g} \mathrm{kg}^{-1}$ bw day ${ }^{-1}$. 